\title{
Aplicação da Escala MacArthur para avaliação do status social subjetivo na Educação Física
}

http://dx.doi.org/10.11606/1807-5509202000020259

\author{
Érico Pereira Gomes FELDEN* \\ Diego Grasel BARBOSA* \\ Sandra Aparecida NOGUEIRA* \\ Pâmella de MEDEIROS* \\ Manoella de Oliveira SANTOS* \\ Thaís Silva BELTRAME*
}

\section{Resumo}

A percepção subjetiva de status social é um importante indicador no estudo do desenvolvimento humano e está associado com o sucesso em atividades cognitivo-motoras e com a saúde. Objetivou-se analisar a aplicação da escala MacArthur para avaliação do status social subjetivo na escola e nas aulas de Educação Física. A amostra foi formada por 194 estudantes, com idades de 11 a 18 anos, matriculados nos anos finais do Ensino Fundamental e no Ensino Médio. 0 entendimento da escala pelos alunos foi avaliado por meio de grupo focal. Após, os resultados da aplicação da escala foram comparados com a percepção autoeficácia, com status subjetivo na sala de aula e com a percepção dos professores. A escala MacArthur adaptada para a Educação Física apresentou bom entendimento por parte dos alunos e correlações significativas com a percepção de autoeficácia e com o status social na sala de aula. A percepção de status social na escola e nas aulas de Educação Física apresentaram correlação positiva $(r=0,409 ; p<0,001)$. A percepção do status social dos alunos pelos professores esteve correlacionada com a percepção dos próprios alunos $(r=0,495 ; p<0,001)$. Valores de 7 ou menos na escala MacArthur indicam alunos com baixa percepção de status social na Educação Física. Desta forma a escala MacArthur apresenta bom entendimento e pode ser utilizada por professores de educação física para identificar alunos com baixa percepção de status social e que devem ser acompanhados com mais atenção.

Palavras-chave: Desejabilidade Social; Educação Física e Treinamento; Adolescentes, Percepção Social.

\section{Introdução}

Uma característica presente em humanos e animais é a escala hierárquica ou o grau de status social que um indivíduo possui perante o grupo, seja na disputa pelo poder ou na marcação territorial ${ }^{1}$. Status é um conceito com múltiplas interpretaçôes que se materializa por meio de parâmetros objetivos como as condiçóes socioeconômicas e de emprego até de aspectos simbólicos de desigualdade considerando construçóes mentais individuais ${ }^{2}$. Estudos científicos tratam da compreensão das relaçóes de parâmetros objetivos e subjetivos de status social na compreensão de comportamentos e no desenvolvimento das pessoas ${ }^{3-5}$.

Em especial o status social subjetivo, caracterizase por um valor auto atribuído a partir da percepção dos indivíduos de sua posição perante a determinados grupos, seja no trabalho, na comunidade ou na escola $^{6,7}$. Especificamente na escola a literatura aponta alguns fatores influenciadores do status social subjetivo como a idade, o tempo em que está na instituição e o sucesso nas atividades acadêmicas e esportivas ${ }^{5,7,8}$. De especial importância, neste contexto, é o fato de que a percepção de status social de crianças e adolescentes esta diretamente ligado ao nível de desempenho que alcançam na execução das habilidades motoras na escola?

No ambiente escolar as aulas de educação física se constituem em momento especialmente importante para análise do status social. Nestas aulas são desenvolvidas atividades importantes para 
a socialização do indivíduo, considerando que o sucesso no desempenho motor é fator importante para a avaliação que os indivíduos têm de si perante os colegas. Nas aulas de Educação Física acontece maior exposição dos alunos e com isso os alunos que possuem pior desempenho motor, evitam situaçôes que demonstram qualquer proficiência motora abaixo da média, retirando-se de brincadeiras, o que pode causar efeitos relativamente duradouros, não apenas pelo prejuízo no desenvolvimento motor, mas também pelo prejuízo nas relaçôes pessoais.

Neste contexto, percebe-se a importância da

\section{Método}

\section{Participantes e procedimentos}

Participaram do estudo 194 estudantes de ambos os sexos, com idades de 11 a 18 anos, regularmente matriculadas no Ensino Fundamental e Ensino Médio ( $6^{\circ}$ ano do Ensino Fundamental ao $3^{\circ}$ ano do Ensino Médio), de uma escola pública estadual do município de Florianópolis - SC. Foi entregue aos estudantes o termo de consentimento livre e esclarecido - TCLE, que foi assinado pelos pais e/ou responsáveis. Além do termo de consentimento assinado pelos pais ou responsáveis os estudantes assinaram o termo de assentimento no qual declararam estar cientes de que apresentavam interesse em participar da pesquisa e compreenderam as atividades que seriam realizadas. A amostra foi selecionada de forma intencional, náo probabilística. Todos os alunos da Unidade Escolar que apresentaram interesse em participar foram incluídos ao estudo. O estudo foi aprovado pelo Comitê de Ética em Pesquisa com Seres Humanos da Universidade do Estado de Santa Catarina (Protocolo 977.281/2015).

Esta pesquisa se dividiu em dois momentos: primeiro foi realizado um grupo focal com 14 alunos, selecionados de forma aleatória na escola com características representativas da população alvo dos diferentes anos e idades. Esta fase teve como objetivo analisar o entendimento das questóes de status social na escola e nas aulas de educação física e foi realizado por três pesquisadores sendo um deles professor da própria escola. Após, procedeu-se aplicação de identificação da percepção do status social dos alunos nos contextos das aulas de educação física. Entretanto é possível identificar ausência de instrumentos válidos e de fácil aplicação num contexto no qual o professor possui normalmente grande número de alunos. Dessa forma, por tratar-se de um instrumento de fácil e rápida aplicação e que vem se demonstrando útil em estudos nas áreas da saúde e ciências humanas o objetivo deste estudo foi analisar a aplicação da escala MacArthur para avaliação do status social subjetivo na Educação Física.

um questionário em sala de aula contendo os instrumentos de pesquisa. Todos os alunos foram convidados a participar desta etapa da pesquisa.

\section{Instrumentos}

O status social foi avaliado por mais de um instrumento com o intuito de comparar os resultados para realizar uma validaçáo concorrente para a escala MacArthur de percepçáo do status social subjetivo (SSS) na escola, adaptada para as aulas de educação física. Os instrumentos utilizados foram:

a) Escala MacArthur de SSS para escola e adaptado para Educação Física;

b) Escala social de status subjetivo na sala de aula (ESSA);

c) Classe econômica (ABEP) e

d) Escala de auto eficácia geral percebida (EAGP).

$\mathrm{Na}$ sequência estão apresentados detalhes das avaliaçóes de status social realizadas:

\section{a) Status Social Subjetivo na escola e na Educaçáo Física}

Com o intuito de avaliar a percepção de status dos estudantes frente aos aspectos do SSS na escola e na educação física, o presente estudo utilizou o instrumento "Escala MacArthur de Status Social Subjetivo: versão para jovens"10. Este instrumento vem sendo utilizado em estudos epidemiológicos recentes ${ }^{11-13}$. 
Esta escala é composta pela imagem de uma "escada social" sendo uma forma de retratar o ambiente escolar. No topo da escada (parte de cima) estão os alunos com o maior respeito, com posição social mais elevada, que tiram as notas mais altas, são bons no esporte e são mais populares. No fundo (parte de baixo) estão as pessoas que poucos respeitam, poucos querem tê-los no time, e que geralmente tem mais dificuldade para aprender os conteúdos. O sujeito marca um "X" no degrau em que percebe se encontrar. Para verificar a pontuação, é marcado " 1 " se houver um " $X$ " no degrau mais baixo ou no espaço acima dele; " 2 ", para o próximo degrau ou no espaço acima, e assim por diante, até o último degrau, que é marcado com "10". Quanto maior a posição marcada na escada maior a percepção do status social do indivíduo.

Para pesquisar o contexto da Educação Física, a escada foi adaptada para retratar o ambiente vivenciado nas aulas de Educação Física. Com base no mesmo enunciado apresentado para a escada da escola os adolescentes deveriam indicar em que lugar eles se percebiam nas aulas de educação física, seguindo o mesmo processo realizado para escola, marcar um "X" no degrau em que percebe se encontrar. Além disto, para o presente estudo foi utilizada a escada de status social subjetivo para os professores indicarem qual posição social que seus alunos se encontravam especificamente na Educação Física. A forma como a escala foi aplicada para a Escola e para as aulas de Educação Física está ilustrada na FIGURA 1.

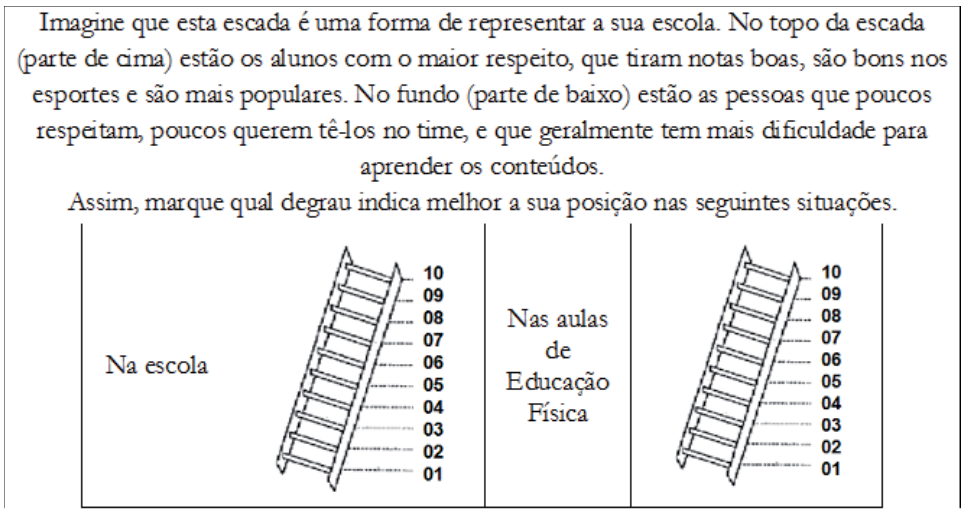

FIGURA 1 - Adaptação da escala MacArthur de status social subjetivo: versão para jovens.

b) Escala social de status subjetivo na sala de aula - ESSA

Para verificar o status social subjetivo na sala de aula entre os alunos utilizou-se uma escala sociométrica proposta por LEvandoski ${ }^{14}$ contendo questóes retrospectivas sobre habilidades específicas percebidas durante o convívio diário. A pontuação encontrada de cada indivíduo reflete ao número de indicaçōes/ citaçóes recebidas pelos outros colegas de turma. As questóes 1, 2, 3 e 4 são direcionadas para as aulas de educação física as questóes 5 e 6 são voltadas para sala de aula. 1. Quem você escolheria para participar do seu time? 2. Quem você não escolheria para participar do seu time? 3. Quem são os alunos mais fortes? 4. Quem são os alunos menos fortes? 5. Quem você escolheria para participar em um trabalho coletivo em sala de aula? 6. Quem você não escolheria para participar em um trabalho coletivo em sala de aula? A questão 1 é oposta a questão 2 , assim como a questão 3 é oposta a questão 4, e questão 5 é oposta a questão 6 . Ainda, as questôes 2, 4, e 6 são inversas quanto maior o número de indicações/citaçôes pior o status do indivíduo citado. Com isso, obtém-se como escore positivo a soma das questóes 1, 3 e 5, da mesma forma, o escore negativo se caracteriza pela soma das questóes 2, 4 e 6 .

\section{c) Classe social}

A determinação das classes sociais foi realizada por meio do Critério de Classificação Econômica Brasil, seguindo as recomendaçóes propostas pela Associação Brasileira de Empresas de Pesquisa ${ }^{15}$. Essa análise considera a posse de bens móveis, ter serviços públicos na sua residência e o grau de escolaridade do chefe da família, distribuindo as famílias nas classes A, B1, B2, C1, C2 D e E. Para um melhor agrupamento dos dados os mesmos foram subdivididos em Classe Alta (A, B1), 
classe média (B2, C1) e classe baixa (C2, D e E).

\section{d) Escala de auto eficácia geral percebida -} EAGP

A auto eficácia geral percebida foi mensurada por meio da Escala de Auto eficácia geral percebida (The General Self-Efficacy Scale) de autoria de Jerusalem e SCHARZER ${ }^{16}$, validada para brasileiros por SouzA e SouzA ${ }^{17}$. Na validação foi observado valor do coeficiente de consistência interna do alfa de Cronbach de 0.81 , indicando a adequação da versão brasileira da Escala de Auto Eficácia Geral Percebida (EAGP). Esta é uma escala likert que avalia o nível de verdade de 1 ("de modo nenhum é verdade") a 4 ("extremamente verdade") de dez questóes de auto eficácia percebida. A pontuação mínima da escala corresponde a 10 pontos e a máxima 40 pontos. Quanto maior a pontuação geral da escala, melhor a auto eficácia percebida do sujeito. As 10 questóes que compóem a escala são: 1 - "Eu consigo resolver sempre os problemas difíceis se eu tentar bastante", 2 - "Se alguém se opuser, eu posso encontrar os meios e as formas de alcançar o que eu quero.", 3 - "É fácil para mim, agarrar-me às minhas intençóes e atingir os meus objetivos", 4 - "Eu estou confiante que poderia lidar, eficientemente, com acontecimentos inesperados", 5 - "Graças ao meu desembaraço, eu sei como lidar com situaçóes imprevistas", 6 - "Eu posso resolver a maioria dos problemas se eu investir o esforço necessário", 7 - "Eu posso manter-me calmo ao enfrentar dificuldades porque eu posso confiar nas minhas capacidades para enfrentar as situaçóes", 8 - "Quando eu sou confrontado com um problema, geralmente eu consigo encontrar diversas soluçóes.", 9 - "Se eu estiver com problemas, geralmente consigo pensar em algo para fazer" e 10 - "Quando tenho um

\section{Resultados}

\section{Grupo focal}

O grupo focal teve como objetivo analisar o entendimento dos alunos com relação à redação proposta na escala MacArthur de status social subjetivo na escola e nas aulas de Educação Física. O grupo focal foi conduzido por três pesquisadores sendo um mediador e dois observadores. Solicitou-se que os respondentes fizessem a leitura das instruçóes e, conforme o entendimento de cada um, sem que houvesse explicaçôes adicionais, assinalassem a questão proposta. Após o preenchimento, problema pela frente, geralmente ocorrem-me várias formas para resolvê-lo."

\section{Análise dos dados}

A primeira parte da coleta se constituiu no grupo focal. Para esta análise foi realizada uma síntese com a impressão das respostas dos três pesquisadores com foco no entendimento das questóes por parte dos alunos.

$\mathrm{Na}$ segunda parte da pesquisa os dados foram analisados utilizando procedimentos estatísticos. A normalidade da distribuição dos dados foi analisada por meio do teste de Kolmogorov-Smirnov, verificada em todas as variáveis. A análise de diferença entre as médias estratificadas pelo sexo foi realizada por meio do teste de U de Mann Whitney. Para correlacionar a percepção de status social na educação física com a auto eficácia percebida, status sócio econômico, SSS na escola e escala de status social em sala de aula, foi utilizado o teste de correlaçáo de Spearman. O coeficiente de consistência interna foi calculado por meio do alfa de cronbach. A Receiver Operating Characteristic (ROC) foi utilizada para identificar possíveis pontos de corte para baixa percepção de status social na escala MacArthur utilizando como referência os alunos piores escores na escola Escala de Auto Eficácia Geral Percebida (tercil inferior da pontuação na amostra). A partir dessa análise, foram apresentados os índices: área sob a curva ROC, valores de sensibilidade e especificidade e pontos de corte para o SSS nas aulas de educação física. Para todas as análises foi considerado um nível de significância de 5\%. Essas análises foram realizadas no software Statistical Package for the Social Sciences (SPSS) for Windows. a mediadora solicitou que os respondentes verbalizassem o entendimento em relação a questão, quais foram as dúvidas surgidas durante a leitura e quais as dificuldades encontradas para o preenchimento. Os integrantes afirmaram que entenderam de forma integral à questão proposta e não tiveram dificuldades na interpretação ou no entendimento dos termos de forma geral. Foi solicitado que os alunos explicassem o que entenderam das questóes citando exemplos o que permitiu confirmar o entendimento das questóes. Após a realização do grupo focal optou-se por 
manter a questão com a mesma redação para aplicação do instrumento, visto que a mesma estava redigida de uma forma clara para o entendimento de alunos com idades de 11 a 18 anos.

\section{Aplicação do questionário}

A amostra foi composta por 194 adolescentes de 11 a 18 anos, em sua maioria de classe média $(53,6 \%)$ e com média de idade de $14,53(2,0)$ anos. Não foram observadas diferenças significativas de idade $(\mathrm{p}=0,188)$ e classe socioeconômica $(\mathrm{p}=0,333)$ entre meninos e meninas. Com relação ao SSS na educação física, os adolescentes apresentaram média de 7,83 $(2,3)$ pontos, sendo que os meninos apresentaram média significativamente maior que as meninas $(\mathrm{p}<0,001)$. Além disso, também foram observadas maiores médias de pontuaçôes do SSS na educação física, pela nota atribuída pelos professores, nos meninos comparados às meninas
( $\mathrm{p}<0,001)$. Já as médias de pontuações do SSS na escola não apresentaram diferenças significativas entre os sexos $(p=0,625)$ (TABELA 1$)$.

Ainda na TABELA 1 pode-se observar que a pontuação média do total da EAGP foi de $28,35(5,7)$ pontos sem apresentar diferença significativa entre os sexos $(\mathrm{p}=0,068)$. Dentre as 10 questôes da EAGP, somente a questão 7 ("Eu posso manter-me calmo ao enfrentar dificuldades porque eu posso confiar nas minhas capacidades para enfrentar as situaçóes") apresentou diferença significativa entre os sexos, sendo que os meninos apresentaram maior média de pontuaçáo $(\mathrm{p}=0,001)$. Além disto, todas as questóes ESSA apresentaram maiores médias de citaçóes nos meninos quando comparados às meninas. Dentre as seis questóes que compóem esta escala foram verificadas diferenças significativas nas questóes: um $(\mathrm{p}<0,001)$, dois $(\mathrm{p}=0,021)$, três $(\mathrm{p}<0,001)$, quatro $(\mathrm{p}=0,009)$ e seis $(\mathrm{p}<0,001)$.

TABELA 1 - Características da amostra com valores médios e desvio padrão.

\begin{tabular}{|c|c|c|c|c|c|}
\hline Variáveis & Total & Masculino & Feminino & p-valor & \multirow{6}{*}{$\begin{array}{l}\text { *Valores expressos em } \\
\text { média (desvio padrão) ou } \\
\text { frequência relativa. }\end{array}$} \\
\hline Idade, anos & $14,53(2,0)$ & $14,37(2,0)$ & $14,74(1,9)$ & 0,188 & \\
\hline Classe socioeconômica, \% & & & & \multirow{4}{*}{0,333} & \\
\hline Baixa & $43(22,2 \%)$ & $20(18,5 \%)$ & $23(26,7 \%)$ & & \\
\hline Média & $104(53,6 \%)$ & $59(54,6 \%)$ & $45(52,3 \%)$ & & \\
\hline Alta & $47(24,2 \%)$ & $29(26,9 \%)$ & $18(20,9 \%)$ & & \\
\hline \multicolumn{6}{|l|}{ ABEP, pontos } \\
\hline SSS na escola, pontos & $7,40(1,6)$ & $7,47(1,6)$ & $7,30(1,7)$ & 0,625 & \\
\hline SSS na Educação Física, pontos & $7,83(2,3)$ & $8,31(2,2)$ & $7,21(2,3)$ & $<0,001$ & \\
\hline \multicolumn{6}{|l|}{ EAGP, pontos } \\
\hline Questão 1 & $2,93(0,9)$ & $3,03(0,9)$ & $2,80(0,9)$ & 0,055 & \\
\hline Questão 2 & $3,16(3,1)$ & $3,37(4,0)$ & $2,87(0.8)$ & 0,197 & \\
\hline Questão 3 & $2,84(0,9)$ & $2,94(0,9)$ & $2,71(0,9)$ & 0,087 & \\
\hline Questão 4 & $2,52(0,9)$ & $2,61(0,9)$ & $2,40(0,8)$ & 0,097 & \\
\hline Questão 5 & $2,65(0,9)$ & $2,75(0.9)$ & $2,53(0,9)$ & 0,063 & \\
\hline Questâo 6 & $3,21(0,9)$ & $3,26(0,9)$ & $3,13(0.9)$ & 0,199 & \\
\hline Questão 7 & $2,98(0,9)$ & $3,18(0,8)$ & $2,71(1,0)$ & 0,001 & \\
\hline Questão 8 & $2,64(0,9)$ & $2,71(0.9)$ & $2,54(0,9)$ & 0,119 & \\
\hline Questâo 9 & $2,89(0,8)$ & $2,92(0,8)$ & $2,84(0.9)$ & 0,571 & \\
\hline Questão 10 & $2,80(0,9)$ & $2,87(0,8)$ & $2,72(0,9)$ & 0,263 & \\
\hline Total & $28,35(5,7)$ & $28,99(5,6)$ & $27,50(5,6)$ & 0,068 & \\
\hline \multicolumn{6}{|l|}{ ESSA, número de citaçôes } \\
\hline ESSA 1 & $5,22(3,8)$ & $6,65(4,1)$ & $3,43(2,4)$ & $<0,001$ & \\
\hline
\end{tabular}

Continua 
Felden EPG, et al.

Continuação

$\begin{array}{ccccc}\text { ESSA 2 } & 3,38(3,2) & 4,06(3,7) & 2,51(2,0) & 0,021 \\ \text { ESSA 3 } & 3,04(4,2) & 4,77(4,8) & 0,80(1,2) & <0,001 \\ \text { ESSA 4 } & 2,83(3,3) & 3,61(3,9) & 1,87(1,9) & 0,009 \\ \text { ESSA 5 } & 3,72(3,3) & 4,22(3,7) & 3,08(2,6) & 0,076 \\ \text { ESSA 6 } & 2,62(2,8) & 3,46(3,3) & 1,52(1,6) & <0,001 \\ \text { Total ESSA positiva } & 12,07(8,6) & 15,66(9,1) & 7,47(5,1) & <0,001 \\ \text { Total ESSA negativa } & 8,77(7,6) & 11,00(8,5) & 5,85(4,8) & <0,001 \\ \text { Status social pelo professor, pontos } & 6,97(1,5) & 7,41(1,5) & 6,43(1,3) & <0,001\end{array}$

O coeficiente de consistência interna foi verificado pelo cálculo do Alpha de Cronbach. A análise entre o SSS na educação física com as 10 questóes EAGP e com o SSS na escola, revelou consistência interna de 0,774 . Este valor foi semelhante ao coeficiente de consistência encontrado no estudo de validação da $\operatorname{EAGP}^{17}(0,810)$. Isto demonstra um alto grau de confiabilidade entre estes três instrumentos, indicando adequação da escala MacArthur para avaliar o SSS na educação física da presente amostra de escolares de 11 a 18 anos.

Com vistas a avaliar a validade externa da escala, foram realizadas análises de correlaçóes lineares entre a escada de SSS na educação física, e a escada de SSS na escola, as 10 questóes da EAGP, as quatros questôes referentes à educação física da ESSA e o nível sócio econômico (ABEP). Verificaram-se correlaçóes significativas do SSS na educação física com o SSS na escola $(r=0,409 ; \mathrm{p}<0,001)$, com as questóes: dois $(\mathrm{r}=0,251 ; \mathrm{p}=0,001)$, três $(\mathrm{r}=0,170$; $\mathrm{p}=0,021)$, quatro $(\mathrm{r}=0,154 ; \mathrm{p}=0,037)$, cinco $(\mathrm{r}=$ $0,227 ; p=0,002)$, sete $(r=0,199 ; p=0,007)$, e dez $(r=$ $0,185 ; \mathrm{p}=0,012)$ da escala EAGP, com o total da EAGP $(r=0,255 ; p=0,002)$, Já com a ESSA o status social na educação física esteve correlacionado com as questóes positivas da escala (TABELA 2).

TABELA 2 - Coeficientes das correlações lineares de Speaman entre o SSS na Educação Física, SSS na escola, EAGP, ESSA e nível sócio econômico.

*coeficiente de correlação de Spearman.

\begin{tabular}{lcc}
\hline \multirow{2}{*}{ Variáveis } & \multicolumn{2}{c}{ SSS na Educação Física } \\
\cline { 2 - 3 } & rho* & p-valor \\
\hline ABEP, pontos & 0,134 & 0,063 \\
SSS na escola & 0,409 & $<0,001$ \\
EAGP, pontos & & \\
Questão 1 & 0,129 & 0,077 \\
Questão 2 & 0,251 & 0,001 \\
Questão 3 & 0,170 & 0,021 \\
Questão 4 & 0,154 & 0,037 \\
Questão 5 & 0,227 & 0,002 \\
Questão 6 & 0,110 & 0,137 \\
Questão 7 & 0,199 & 0,007 \\
Questão 8 & 0,101 & 0,174 \\
Questão 9 & 0,134 & 0,069 \\
Questão 10 & 0,185 & 0,012 \\
Total & 0,255 & 0,002 \\
ESSA, número de citaçôes & & \\
ESSA 1 & 0,351 & $<0,001$
\end{tabular}

Continua

264 • Rev Bras Educ Fís Esporte, (São Paulo) 2020 Abr-J un;34(2):259-69 
Continuação

\begin{tabular}{ccc} 
ESSA 2 & $-0,137$ & 0,061 \\
ESSA 3 & 0,291 & $<0,001$ \\
ESSA 4 & $-0,60$ & 0,413 \\
ESSA 5 & 0,149 & 0,039 \\
ESSA 6 & 0,016 & 0,829 \\
Total ESSA positiva & 0,332 & $<0,001$ \\
Total ESSA negativa & $-0,071$ & 0,346 \\
Status social pelo professor, pontos & 0,495 & $<0,001$ \\
\hline
\end{tabular}

Quando comparado a percepção do SSS do aluno com relação a percepção do status subjetivo dos alunos pelo professor, observamos uma diferença significativa entre as médias, sendo que os professores de educação física perceberam o status social de seus alunos nas aulas de educação física de uma forma inferior quando comparado a percepção dos próprios alunos nas mesmas aulas (FIGURA 2).

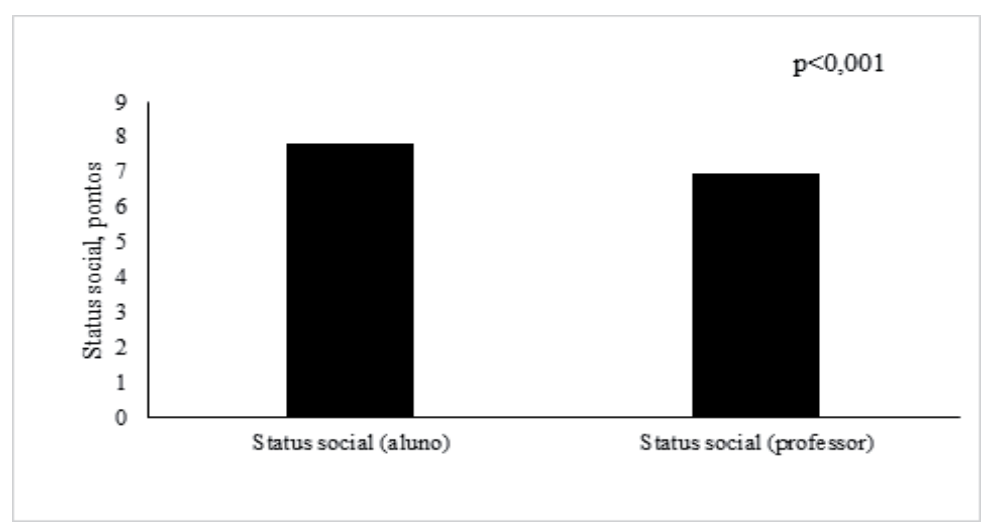

FIGURA 2 - Diferença da pontuação da escala MacArthur de Status social pela visão dos alunos e dos seus professores.

A análise Receiver Operating Characteristic (ROC) da escala MacArthur considerando como referência o tercil inferior da EAGP indicou a pontuação 7 como melhor ponto de corte da escala
MacArthur para identificar baixa percepção de autoeficácia (tercil inferior). Assim, valores de 7 ou menos na escala MacArthur indicaram alunos com baixa auto eficácia (TABELA 3). 
TABELA 3 - Ponto de corte SSS na educação física para altos valores de auto eficácia da amostra.

\begin{tabular}{lcc}
\hline \multirow{2}{*}{ Escala MacArthur } & \multicolumn{2}{c}{ Baixa autoeficácia percebida } \\
\cline { 2 - 3 } & Meninos & Meninas \\
\hline Área & 0,663 & 0,658 \\
p-valor & $<0,001$ & 0,001 \\
Ponto de corte, pontos & 7 & 7 \\
Sensibilidade (IC 95\%) & $76,0(66,2-84,2)$ & $72,5(63,1-80,6)$ \\
Especificidade (IC 95\%) & $52,2(36,9-67,1)$ & $51,5(33,6-69,2)$ \\
\hline
\end{tabular}

\section{Discussão}

O objetivo geral deste estudo foi analisar a aplicação da escala MacArthur para avaliação do SSS na educação física. Para contemplar este objetivo, utilizaram-se instrumentos já observados na literatura como a ESSA, a EAGP e o SSS na escola, com intuito de verificar a viabilidade de aplicaçáo da escala MacArthur no contexto das aulas da educação física. Neste sentido, verificaram-se correlaçóes entre as questóes positivas da ESSA com o SSS na educação física. Além disto, foi proposto ponto de corte de 7 pontos para o SSS na educação física para altos valores na EAGP.

No que se refere ao status em sala de aula, percebeu-se que ao mesmo tempo que os meninos foram mais escolhidos para participar dos times nas aulas de educação física, foram também os menos escolhidos. Ou seja, os meninos se encontram nos extremos na ordem de escolha dos times, sendo geralmente os primeiros e últimos a serem escolhidos. Da mesma forma ocorreu com a percepção dos mais e menos fortes do grupo.

O maior envolvimento nas aulas por parte dos meninos pode ser explicada pelo fato de que este grupo tende a estar mais envolvido em atividades físicas quando comparados às meninas ${ }^{18}$. Além disto, Uchoga e Altmann ${ }^{19}$, apresentaram uma possível explicação para as meninas se colocarem em posiçóes secundárias e menos ativas durante os jogos na educação física, no sentido de que questóes como expectativas corporais, sucesso na obtenção de pontos nos jogos e papéis decisivos nas jogadas, estáo mais presentes nos meninos do que nas meninas. Isso os torna mais suscetíveis a avaliaçóes, tendo em vista que os meninos são mais competitivos por dominância social e status, estando mais expostos às avaliaçôes dos colegas?.
Ainda, observou-se que os meninos apresentaram maior SSS nas aulas de educação física em comparação com as meninas. Levando-se em consideraçáo que os meninos foram os mais e menos citados tanto para escolha e participação dos times, quanto para serem caracterizados como mais e menos fortes, supóe-se que as meninas da presente amostra não participam ou não se envolvem suficientemente nas aulas de educação física. Este dado pode ser reforçado também, pela percepção mais alta do status social na educação física pelos professores nos meninos. Isto remete a uma questáo historicamente construída pela sociedade no sentido de considerar as meninas menos habilidosas para a prática esportiva quando comparadas aos meninos, e o ambiente escolar pode reforçar ainda mais este pensamento ${ }^{20}$. Em contrapartida os meninos foram menos citados para fazer trabalhos na sala de aula. Desta forma, sugere-se que os alunos independentes do sexo, prefiram fazer trabalho com as meninas. Além disso, estudos têm evidenciado que os meninos apresentam um pior desempenho escolar e maiores dificuldades de aprendizado ${ }^{21,22}$.

No que diz respeito ao SSS na educação física, observaram-se correlaçóes positivas com a frequência de citaçóes no ESSA e com o SSS na escola. Supóe-se com isto, que os escolares que possuem alto SSS na educação física, também são percebidos numa escala hierárquica elevada com relação ao ambiente escolar como um todo. Isto permite supor que o modo como os adolescentes se percebem na educação física reflete também na forma como seus pares o percebem na escola. Levando-se em consideração que o SSS tem grande importância para o bem estar físico e mental dos escolares, Osteberg ${ }^{23}$ em estudo com 13.932 
crianças escocesas, verificou que quanto maior era posição social da criança, mais incomum era seu mal estar mental. Sendo o contrário verdadeiro, quanto menor era a posição de status em relação aos seus pares, menor seria sua auto avaliação de saúde na vida adulta. Diante disso, as informaçóes acerca do SSS na educação física dos escolares da presente amostra podem servir como base para o professor dessa disciplina intervir pedagogicamente, a fim de dirimir dificuldades relacionadas à baixa participação daqueles com baixo SSS.

Além do SSS na educação física ser importante para indicar a posição social percebida na escola e para o bem estar físico e mental do escolar, pode também ser um indicador importante da auto eficácia geral percebida por estes sujeitos. Poderse-ia esperar que diante das diferenças do SSS na educação física entre meninos e meninas, pudessem existir também diferenças na auto eficácia. Neste interim, somente a questão 7 "Eu posso manter-me calmo ao enfrentar dificuldades porque eu posso confiar nas minhas capacidades para enfrentar as situaçóes" foi superior nos meninos. No entanto, Souza e Souza ${ }^{17}$, em estudo de validação da EGEAP para o Brasil, não verificaram diferenças entre os sexos. Estas discrepâncias podem estar relacionadas às diferenças de idades das amostras dos dois estudos. Ainda, no estudo de validação, os autores testaram a diferença somente da pontuaçáo total da EAGP, enquanto que no presente estudo foram testadas também as diferenças de cada questão entre os sexos.

Não obstante, foram verificadas correlaçóes positivas entre o SSS na educação física e a escala de auto eficácia percebida, tanto na pontuação total quanto em mais de $50 \%$ das questóes. Supóe-se com isso, que a auto eficácia percebida parece possuir estreita relação com o SSS na educação física. Deste modo e sabendo-se da importância da auto eficácia para a crença da própria competência para lidar com uma ampla gama de demandas estressantes ou desafiadoras ${ }^{24}$, e que grande parte destas demandas geralmente são encontradas nas aulas de educação física, foi verificado que os adolescentes com 7 pontos ou menos no SSS na educação física apresentaram baixos valores de auto eficácia geral percebida. Deste modo, sugere-se com estes resultados que a aplicação da escala MacArthur para educação física, pode ser uma importante ferramenta para indicar alunos com baixa auto eficácia geral e com isso, o professor de educação física poderá realizar um planejamento e orientação individualizada quanto às atividades a serem ministradas ao longo do ano letivo.

Pontuaçóes iguais ou abaixo de 7 no SSS na educação física apresentaram capacidade preditiva para a baixa auto eficácia nos escolares. Ainda, levando-se em consideração que a escala MacArthur para a educação física apresentou correlaçóes importantes com a auto eficácia, status subjetivo na sala de aula e SSS na escola, sugerem-se que professores e pesquisadores da área da educação física utilizem este instrumento como suporte para avaliar e intervir sobre escolares com baixa auto eficácia e baixo status social. Aponta-se como principal limitação do presente estudo o delineamento de corte transversal, em que não foi possível estabelecer relaçóes de causalidade entre as variáveis investigadas. 


\section{Abstract}

Application of the MacArthur scale for evaluation of the subjective social status in physical education

The subjective perception of social status is an important indicator in the study of human development and is associated with success in cognitive-motor activities and health. The aim of this study was to analyze the application of the MacArthur scale to evaluate subjective social status in school and physical education classes. The sample consisted of 194 students, aged 11 to 18 years, enrolled in the final years of elementary and high school. The students' understanding of the scale was evaluated through a focus group. Afterwards, the results of the application of the scale were compared with the self-efficacy perception, with subjective status in the classroom and with the teachers' perception. The MacArthur scale adapted to physical education presented good understanding on the part of students and significant correlations with the perception of selfefficacy and social status in the classroom. The perception of social status in school and physical education classes presented a positive correlation $(r=0.409, p<0.001)$. The perception of the students' social status by the teachers was correlated with the students' own perception $(r=0,495, p<0.001)$. Values of 7 or less on the MacArthur scale indicate students with low perceptions of social status in physical education. In this way the MacArthur scale presents good understanding and can be used by physical education teachers to identify students with low perception of social status and who must be followed with more attention.

KeYwords: Social Desirability; Physical Education and Training; Adolescents; Social Perception.

\section{Referências}

1. Morris D. O Macaco Nu: um estudo do animal humano. Rio de Janeiro: Record; 1967.

2. Ollivier M. Status em sociedades pós-modernas: a renovação de um conceito. Lua Nova, São Paulo. 2009;77:41-71.

3. Adler NE, Epel ES, Castellazzo G, Ickovics JR. Relationship of subjective and objective social status with psychological and physiological functioning: Preliminary data in healthy, White women. Health Psychol. 2000;19(6):586.

4. Medeiros P, Zequinão MA, Cardoso FL. Bullying e a relação entre atividade física e coordenação motora: uma revisão sistemática. Cinergis. 2014;15(3).

5. Levandoski G, Cardoso FL. Imagem corporal e status social de estudantes brasileiros envolvidos em bullying. Rev Latinoam Psicol. 2013;45(1):135-45.

6. Adler N, Singh-Manoux A, Schwartz J, Stewart J, Matthews K, Marmot MG. Social status and health: A comparison of British civil servants in Whitehall-II with European- and African-Americans in CARDIA. Soc Sci Med. 2008 Mar;66(5):1034-45.

7. Crosnoe R, Frank K, Strassmann A. Gender, body size and social relations in American high schools. Soc Forc. 2008 Mar;86(3):1189-216.

8. Oldehinkel AJ, Rosmalen JG, Veenstra R, Dijkstra JK, Ormel J. Being admired or being liked: Classroom social status and depressive problems in early adolescent girls and boys. J Abnorm Child Psychol. 2007;35(3):417-27.

9. Medeiros P, Zequinão MA, Cardoso FL. Influência do desempenho motor no status social percebido por crianças . Rev Bras Educ Fis Esporte. 2015;

10. Goodman E, Adler NE, Kawachi I, Frazier AL, Huang B, Colditz GA. Adolescents' perceptions of social status: Development and evaluation of a new indicator. Pediatrics. 2001 Aug;108(2).

11. Spence ML, Costello C, Fitzhugh E, Greer B, Muenchen R, Gibbs R, et al. Weight status, dietary intake, physical activity, and subjective social status of adolescents in grades 7-12 participating in a national creative competition. FASEB. 2012;26(1 Supplement):lb355-lb.

12. Sweeting H, West P, Young R, Kelly S. Dimensions of adolescent subjective social status within the school community: Description and correlates. J Adolesc. 2011 Jun;34(3):493-504.

13. Subramanyam MA, Diez-Roux AV, Hickson DA, Sarpong DF, Sims M, Taylor HA, et al. Subjective social status and psychosocial and metabolic risk factors for cardiovascular disease among African Americans in the Jackson Heart Study. Soc Sci Med. 2012 Apr;74(8):1146-54. 
14. Levandoski G. Análise de fatores associados ao comportamento bullying no ambiente escolar: Características cineantropométricas e psicossociais: Dissertação de Mestrado em Ciencias do Movimento Humano, Universidade do Estado de Santa Catarina, Florianópolis, SC, Brasil; 2009.

15. Associação Brasileira de Empresas de Pesquisa. Critério de classificação econômica Brasil [Internet]. São Paulo: ABEP; 2014 Disponível em: <www.abep.org> Acessado em 10 de novembro de 2015.

16. Jerusalem M, Schwarzer R, Schwarzer R. Self-efficacy as a resource factor in stress appraisal processes. Self-efficacy. 1992:195-213.

17. Souza I, Souza MAd. Validação da escala de autoeficácia geral percebida. Rev Univ Rur. 2004;26(1-2):12-7.

18. Seabra AF, Mendonça DM, Thomis MA, Anjos LA, Maia JA. Determinantes biológicos e sócio-culturais associados à prática de atividade física de adolescentes. Cad Saude Pública. 2008;24(4):721-36.

19. Uchoga LAR, Altmann H. Educação física escolar e relaçóes de gênero: diferentes modos de participar e arriscar-se nos conteúdos de aula. Rev Bras Cienc Esporte. 2016;38(2):163-70.

20. da Rocha Matos N, Brasileiro GS, Rocha RT, Neto JLC. Discussão de gênero nas aulas de Educação Física: uma revisão sistemática. Motrivivência. 2016;28(47):261-77.

21. Carvalho MPd. Sucesso e fracasso escolar: uma questão de gênero. Educ Pesq. 2003;29(1):185-93.

22. Capellini SA, Tonelotto JMdF, Ciasca SM. Medidas de desempenho escolar: avaliação formal e opinião de professores. Estud Psicol (Campinas). 2004;21(2):79-90.

23. Östberg V. Children in classrooms: Peer status, status distribution and mental well-being. Soc Sci Med. 2003;56(1):17-29.

24. Luszczynska A, Scholz U, Schwarzer R. The general self-efficacy scale: multicultural validation studies. J Psychol. 2005;139(5):439-57.

ENDEREÇO

Érico Felden Pereira

Rua Simone Pachoal, 350 - Coqueiros 88080-350 - Florianópolis - SC - BRASIL

E-mails: ericofelden@gmail.com

Submetido: $16 / 12 / 2016$

Revisado: 19/09/2017

erico.felden@udesc.br

Aceito: 23/ 05/2018

Rev Bras Educ Fís Esporte, (São Paulo) 2020 Abr-J un;34(2):259-69• 269 